\title{
TO REACH THE LIGHT: THE MONUMENTAL BYZANTINE STAIRS OF CAESAREA, A CONSERVATION AND RESTORATION PROJECT
}

\author{
N. MAKLADA ${ }^{1 *}$, S. HADID $^{2}$, D. ABUHATSIRA ${ }^{3}$, P. GENDELMAN $^{4}$, Y. OZ $^{5}$, AND D. $^{2}$ \\ SIBONI $^{6}$ \\ ${ }^{1}$ Conservation Researcher, Conservation Department, Israel Antiquities Authority (IAA) \\ Rockefeller Musem, P.O.B 586, Jerusalem 91004, Israel \\ e-mail: nabe26@gmail.com \\ ${ }^{2}$ Rappaport Faculty of Medicine, Technion-Israel Institute of Technology \\ ${ }^{3}$ Conservation Planning Office, 3 Har Shlomo, St, Or Akiva 306000, Israel \\ ${ }^{4}$ Archaeological Research Department, Israel Antiquities Authority \\ ${ }^{5}$ Schaffer \& Ronen, Conservation Engineering, 33 Jaffa St, Jerusalem 94221, Israel \\ ${ }^{6}$ Conservation Manager, Conservation Department, Israel Antiquities Authority
}

Keywords: Caesarea, Byzantine Staircase, Maintenance, Sandstone, arch bridge, vault.

\begin{abstract}
Ancient Caesarea has founded in the years 25-10 BC and named after Emperor Augustus. Throughout history, from the early Roman until the Byzantine period, Caesarea was a major city and one of the largest and most important port cities in the Mediterranean. During the Byzantine period, the city encompassed an area three times larger than that delimited by the Herodian wall and became an important center of Christianity. The monumental stairs led to the Byzantine Octagonal Church built upon giant arch above the remains of the enormous Roman stairs of Augustus temple. Stairs led a large number of people from the vast harbor, to the Temple platform. The Byzantine arch located 17 meters from the ancient quay, is 8 meters width and 4-meter long, built with specific technology from local sandstone named Kurkar. The arch fall after the Byzantine period and the staircases severely damaged due to the long exposure of almost 1500 years and environmental conditions such as capillary rise, daily winds carrying sand, high temperature, moisture, salts, and deliberate destruction, for instance, stones robber and collapse parts from the wall. The characteristics of the Kurkar with sustained deterioration and this environmental condition have led to different conservation problems, at various levels of severity erosion, the disintegration in both bonding materials and stones. The conservation measures' purpose is to stop the ongoing weathering process and prevent a deterioration state of the staircases, to restore the arch and stabilize the structure of the stairs to carry 48 tons of the restore arch. The findings of the project show that a suitable solution to ensure effective and sustainable protection of complicated staircases structure from destruction and various weathering condition to carry new massive arch depends on understanding the
\end{abstract}


ancient application of building technologies and techniques, the use of original bonding material, integrated monitoring, and ongoing maintenance.

\section{INTRODUCTION}

The city of Caesarea was founded adjacent to the Mediterranean Sea between Jaffa and Dor (Fig. 1), on the site of the abandoned Hellenistic town "Straton's Tower". Herod king of Judea under Roman aegis made Caesarea the administrative capital and the main harbor of his vast kingdom. The city was named after Caesar Augustus, Herod's patron, the first Roman emperor. It continued to develop and prosper even more in the Byzantine period. In this magnificent port city and its rural hinterland, "prices are low, their abundance obtains" (Jerusalem Talmud, Kil'ayim 9:4, 32c; Ketubot 12:3, 35d).

In the Byzantine era, the city reached its ultimate expansion and encompassed an area three times larger than that delimited by the Herodian wall. The archaeologist Patrich (2018) noted that Until the fifth century, the city developed and spread beyond the course of the Herodian wall without having an outer defense wall and covered an area of some 275 acres

The Roman temple has built on a Kurkar hill rising high in the center of the city above the port. The foundation remains of the rectangular temple were placed in it faced the port. The architectural elements found dispersed, enable the researchers to reconstruct a Corinthian temple with six columns on the front (hexastyle) [3]. With the spread of Christianity and the

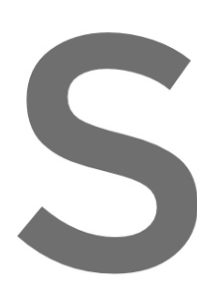
oppression of pagani

and his stones slowly foundation level [2]. I

the ravaged site. Like

church of Mary Theotol

that bore the walls and a
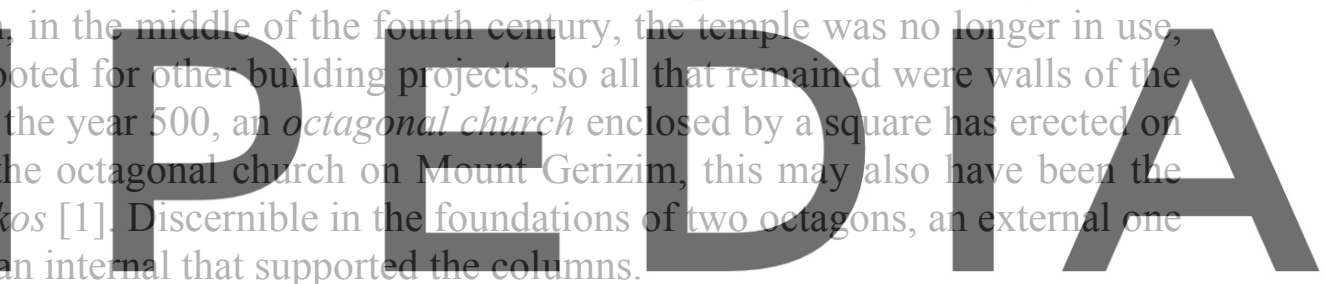

The Temple and after that, the Octagonal church situated on an elevated platform formed the

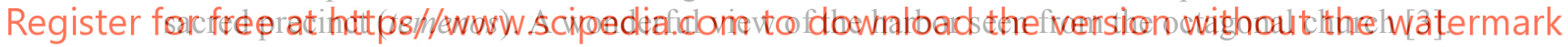

The eastern retaining wall was curvilinear, the western one ran parallel to the harbor quay, the south and north retaining walls ran perpendicular to it boundaries a large area. The Temple platform was expanded and leveled by a network of walls and a longitudinal vault system on the platform west side [1]. Four large one on the north and south side in dimensions of $25 \times 5 \mathrm{~m}$, and six smaller massive east-west vaults $20 \times 2.5 \mathrm{~m}$, on the front of the temple, adjacent to the altar, and part of the construction staircase system on the temple's central axis, proceeding to the temple above [3]. It was founded on bedrock and built of finely dressed Kurkar ashlars with draft margins surrounding a high or shallow central boss.

At the edge of the piazza in the Roman era adjacent to the quay and on the temple's symmetrical axis, was a massive pier, 20-meter width, and 10-meter length, that housed a staircase leading up to the temple platform [1]. Access to it was from the eastern side of the pier. Thus, the rise began from east to west and continued higher at 180 (degree) turn from west to east. This massive pier supported a bridge with two vaults that existed in the interval between the visible pier and the western (temenos) wall, leading to the temple platform. This massive Roman pier disassembled in the Byzantine period, and a new staircase pier system built in its place, the new system included one vault and elongated pier from east to west in dimensions of 10-meter width and 20 meters long [3]. The Byzantine staircase built in the center of the piazza 
and went 8 meters inside the quay climbing the stairs begins from the new extension at the western side to the east this massive pier supported a bridge of vault leaning against six eastwest vaults from the Roman period and continued higher proceeding to the church above the platform.
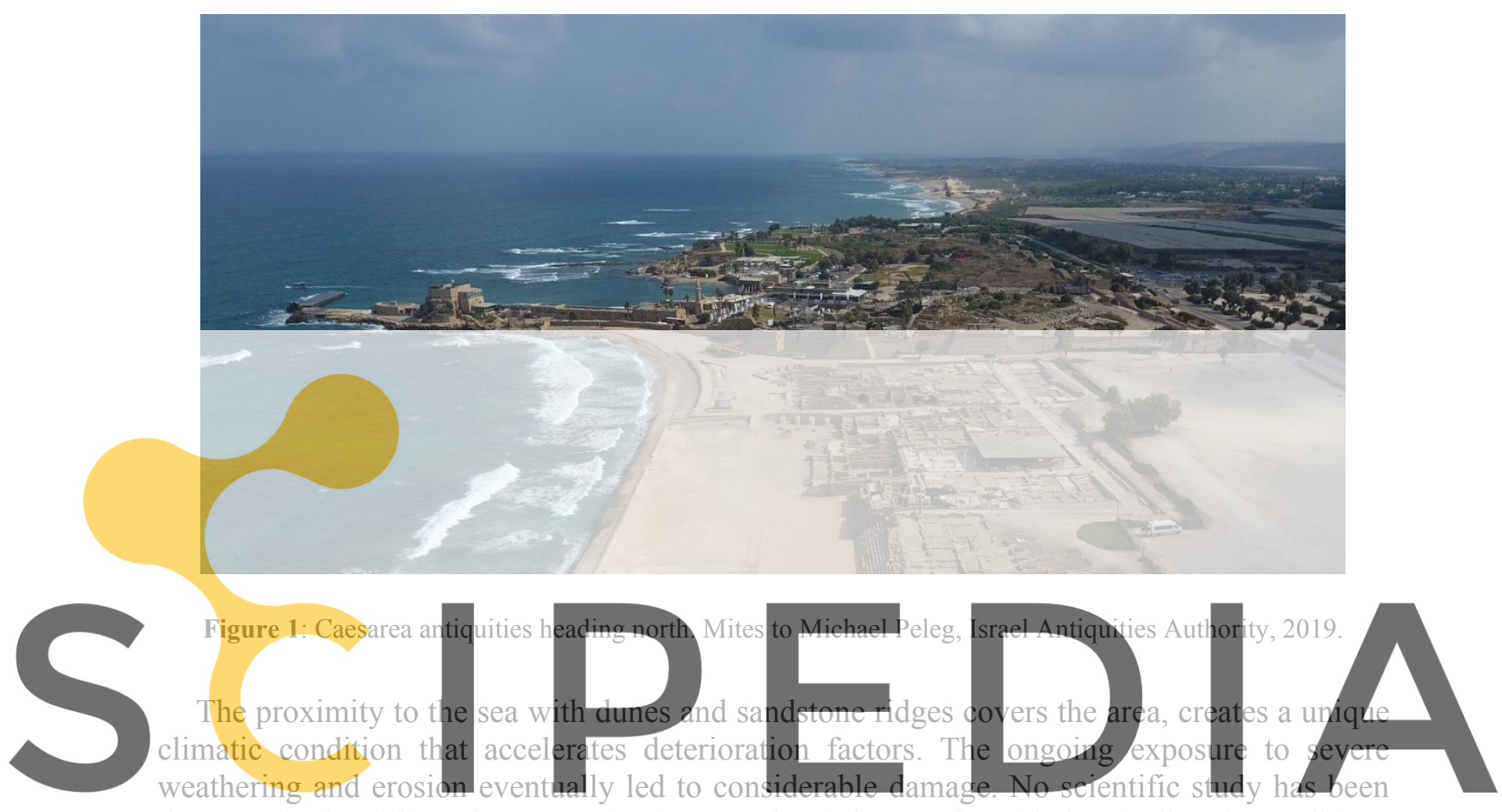

done on the durability of conservation intervention influence found in harsh climatic conditions

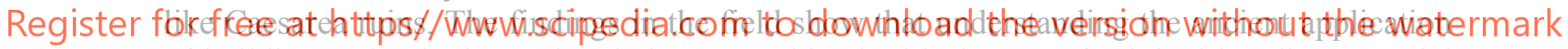
of building technologies and techniques combined with the use of original bonding material and traditional building technologies reduces damage to various elements and stabilizes the structure to carry a new massive arch, in addition to the need for constant maintenance.

The monumental Byzantine stairs Conservation project started in 2017, applying original bonding materials and traditional building techniques that were implemented with analysis of the archeological and architectural findings to deal with the deterioration and conservation intervention. This case study aimed to resuscitate and stabilize the (temenos) wall with the pier and stop the weathering factors by keeping a complicated structure consisted of Kurkar stone; each one endures centuries of history.

\section{BUILDING TECHNOLOGY}

Caesarea city built from local sandstone named Kurkar 2000 years ago, the stone hewn from the hills around the city. In Israel, the sandstone ridges existing near the Mediterranean Sea and parallel to it, from the north to the south. The ancient architectures and engineers use the local stone to build the city and plaster it with white plaster [3].

The monumental staircase led to the Byzantine Octagonal Church built from two different 
structures; an enormous pair on the west side near the quay and six smaller massive east-west vaults $20 \times 2.5 \mathrm{~m}$ in the east side adjacent to the alter on the front of the Church central axis. The structures connected with a giant arch in dimensions; 8 meters width, 8-meter-high, and 4-meter long (Fig. 2).

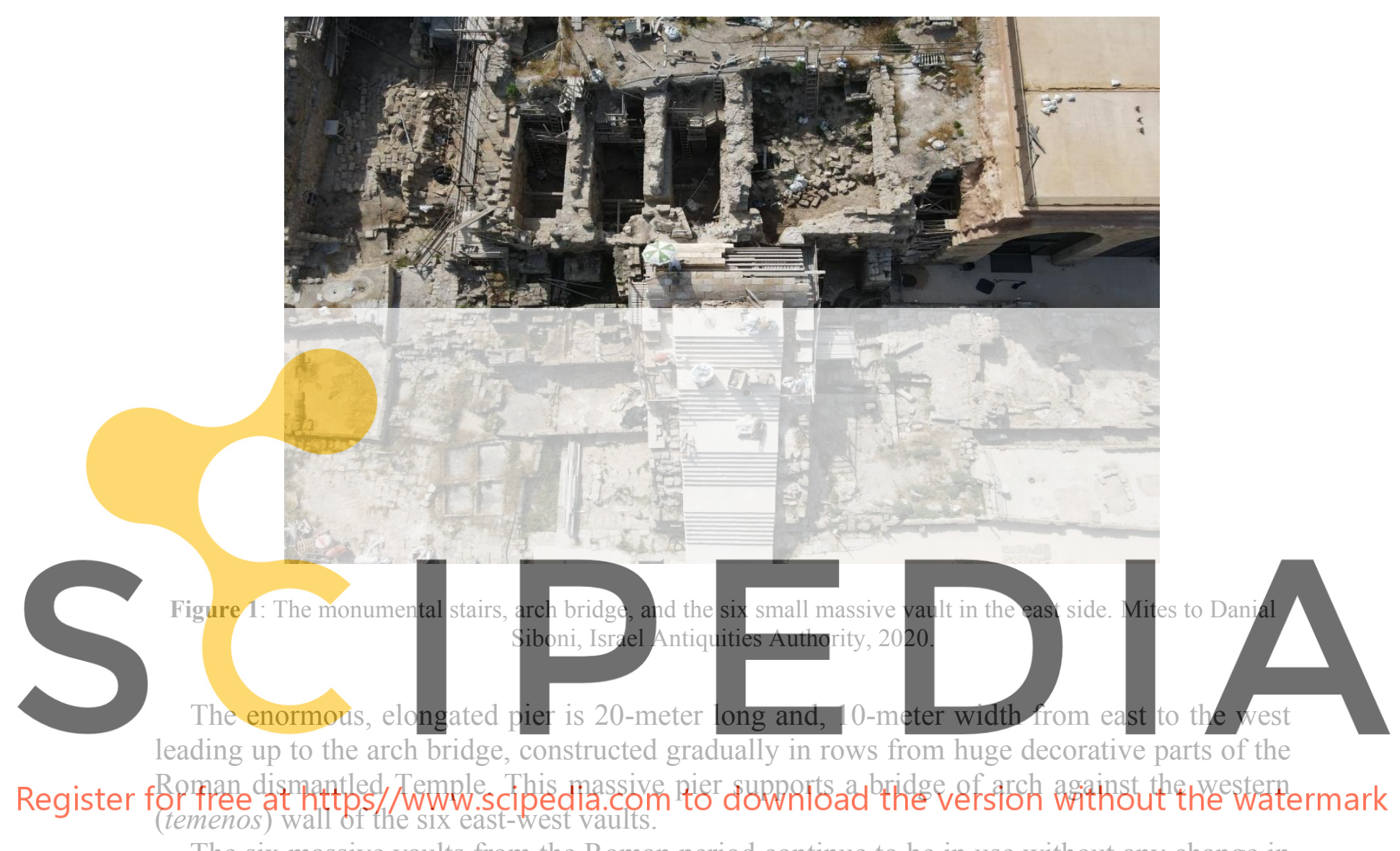

The six massive vaults from the Roman period continue to be in use without any change in structure also in the Byzantine period. This vaults system bounded with four big vaults $25 \times 5 \mathrm{~m}$ on both the north and south sides supported the Roman Temple platform (Fig. 2). These vaults were founded on bedrock and built of finely dressed Kurkar ashlars [1]. The surrounded wall is $2.6 \mathrm{~m}$ in thickness and constructs from ashlars stones with draft margins surrounding a high or shallow central boss on the exterior side and ashlars stone without boss internal. The vaults built above the wall in width $1.5 \mathrm{~m}$ and including passages with two arches in each wall the arch width of $2.3 \mathrm{~m}$ construct from ashlar stones, each one of the vault entrance and windows to the port at the west side. These walls and vaults built with different construction technology using ashlar stone integrated with lime, earth, and rubble casting, a similar technique on the first five vaults the casting incorporated in the carried wall its begins and ends at the height range of the aisles arch, despite the last vaults casting together with the carried wall (Fig. 2).

The following table illustrate the carried walls number and the different on construction technology, from top to bottom. 
Table 1: The table demonstrate the six vault construction material order from top to bottom.

\begin{tabular}{llll} 
Carried wall & 1 and 2 & 3 and 4 & 5 \\
\hline Vault & Stone & Stone & Casting \\
Ashlar stone & 4 lines & 1 line & - \\
Casting & $80-90 \mathrm{~cm}$ & $180-200 \mathrm{~cm}$ & $200 \mathrm{~cm}$ \\
Ashlar stone & 6 lines & 6 lines & 6 lines
\end{tabular}

\section{ASSESSMENT PROCESS}

Considering approaches to restore, conserve, or other forms of change, it is vital and fundamental to the conservation planning process to understand the significance of a historic building or objects and the values that contribute it, tangible and intangible.

The condition survey should include an investigation work to determine the original construction and materials, archaeological analysis, causes of decay and deterioration, evaluate threats, and identify priorities for intervention.

Determining conservation and restoration requirements adopted decisions taken regarding appropriate types and levels of intervention depend upon sufficient information being gathered during the assessment process to grant long-term care for the heritage properties.

\subsection{Environmental problems}

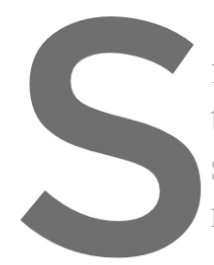

Structures, elemen

factors that determine

typically is very complex

since it includes suffer

repairs. Also, they are in

Try to understand patterns of complex environn
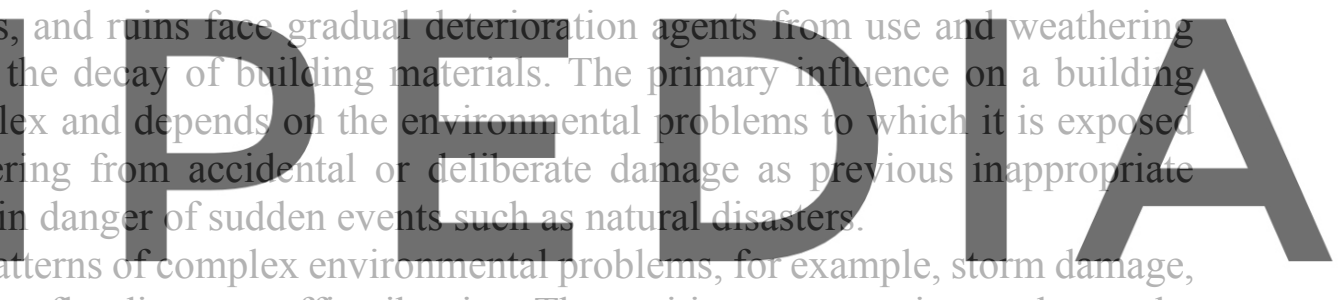

pollution, moisture, salts, flooding, or traffic vibration. The position, construction, and even the

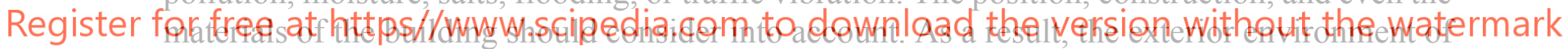

any building will always be unique [6].

\subsubsection{Moisture}

Water is one of the most critical factors in the deterioration of the stone. Like all porous building materials, the stone is hygroscopic, meaning it has a strong attraction to water and will absorb moisture from the atmosphere or the ground until it reaches equilibrium with its environment [2]. Inside a block of stone, water can exist as a liquid, as a vapor, or as ice in cold condition. While atmospheric humidity increases, porous stones absorb water vapor readily, which it will release as the humidity drops. If the stone is coldish and the air is damp, water vapor will condense to form a film of liquid water on the surface or inside the pores.

Groundwater can be drawn into stone by capillary action, and rainwater can penetrate through building flaws such as open joints, cracks, or soil [4]. In the winter, the source of moisture is a catastrophic event such as a storm, flood, and sea waves. It is critical to many deterioration processes, no matter how they penetrate to stone masonry - through the bonding material or the stone itself. The most common consequences are:

- Transport and crystallization of salts on and within the stone. 
- Swelling of clay minerals that can lead to splitting and cracking.

- Growth of plants.

\subsubsection{Salts}

Contaminants existing in all building stones, and soluble salts are one of the most commons. Their origin is different, including soils, bonding material, biological matter decayed, sea spray, waves, and pollution.

Some will be inherent in the stone, having been incorporated during formation or carried in later by percolation, others may have been absorbed during construction or repair, chiefly from mortars, but most are carried in after building by rain, groundwater, and waves [2]. Liquid water can travel rapidly within the pores at the stones and bonding material, or the surface of the stone. They were dissolving salt and carrying them through the rock fabric and depositing them wherever the liquid flow stopped. Surface crystallization 'Efflorescence' can be unsightly, usually made up of very soluble salts. Less-soluble salt may crystallize within the pores 'Cryptoflorescence', breaking apart the stone, crumbling bonding material, causing powdering and flaking. Cryptoflorescence may also occur where there is rapid drying, such as on the corners where the wind is faster [6].

Damage to stone is worst where there frequent wetting and drying, resulting in cycles of crystallization and dissolution. Salt damage will tend to be apparent in the evaporation zone: the various area between being damp to dissolve the salts and dry enough for them to crystallize

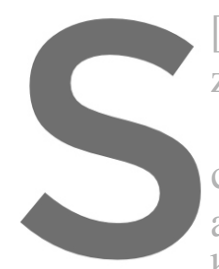
[5]. These salts may dissolve again when the avai
zones will often give a clue to the source of the
Salt affected by many factors, including the
characteristics of the pores, the pore moisture
ambient air, the temperature of the stone, and the behavior is still not wholly understood regarding

Generally, salt problems will often be active over a wide range of ambient conditions,
Register for free at https//WwW.scipedia.com to download the version without the watermark

\subsubsection{Vegetation}

It is unquestionably that vegetation in certain circumstances may be masonry protective; indeed, it is benign in several cases where plant growth does damage to the stone. Plants are one of the most common problems in the masonry, existing different plants in various sizes growing on the monuments [6]. Annual and seasonal plants proliferate in cracks but usually die before reaching a large extent, do not cause them, and will not grow in a way that causes more damage. Woody and perennials founded on vertical and horizontal surfaces can be vigorous, producing masses of stems that can dislodge the stone.

Usually, vegetation presence can be indicative of a problem such as open joints, cracks, and water ingress. Trees and shrubs can damage masonry if they are allowed to establish themselves. Plants grow in the soil adjacent, and on the top of the masonry, the roots entered the bonding material between the stones, which is the relatively soft material, disassembled and pushed the rocks around them and expedited the process of weathering.

\subsubsection{Maritime environment}

Waves can be devastating since it arrives with no warning. It can introduce soluble salts and 
other contaminants into the masonry. The greatest danger arises from the drying-out period after the stream. The Mediterranean Sea waves caused by coastal storm-surge are a significant weathering factor. During the winter, waves crash over the masonry causing erosion of mortar and stones, also bring lots of salts into the ruins [5].

Wind with sand and salt causes rapid and increased erosion of bonding materials and stones. Fragments of water splashed into the air from waves able to reach considerable distances carried on the winds. This maritime environment has to be taken into account when trying to understand a problem related to chlorides.

Temperature plays a significant role in several decay processes, such as salt crystallization damage caused by quick evaporation in saturated porous stone, differential expansion and contraction of dense salt-laden crusts on sandstones and limestones.

Deterioration and destruction factors mentioned above, cause erosion and crumbling bonding material, including stones. There is essential to think from a comprehensive perspective about these various conservation problems in order to find suitable solutions.

\section{CARE AND MAINTENANCE}

The successful repair of stone relies on understanding the practical issues relating to the material and its environment, also considering those within the context of its historical and cultural significance. The priority of a stone conservation program is to deal with the causes of any ongoing deterioration; this may well involve work to other parts of the building and require the input of specialist other than stono conservation or masons. Once the underlying causes of
deterioration are detected, treatment and repair options can consider.

Register for free at https//www.scipedia.com to download the version without the watermark

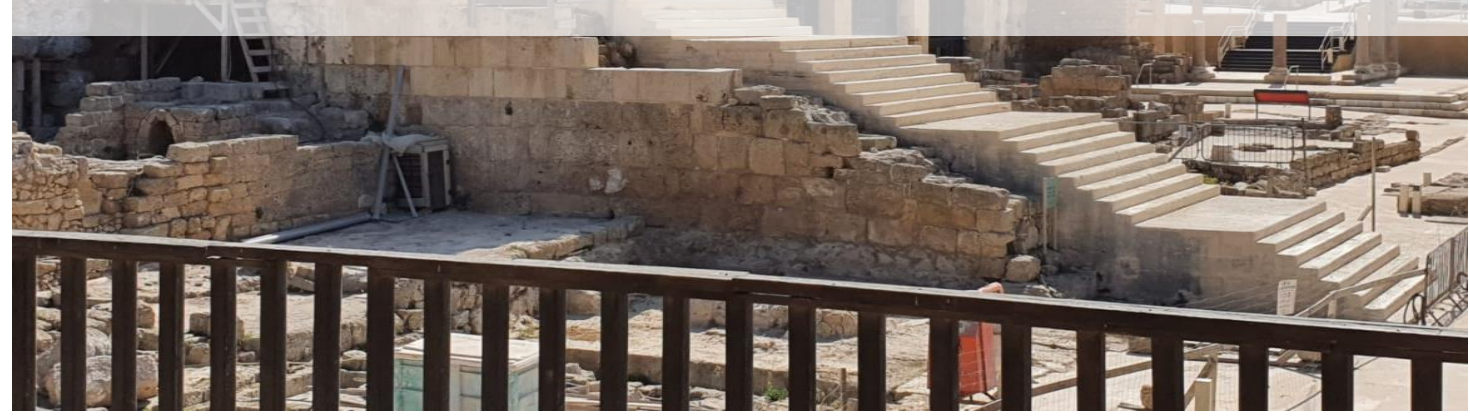

Figure 3: The stairs and the arch bridge heading south. Mites to Danial Siboni, Israel Antiquities Authority, 2020 .

\subsection{Vegetation Uprooting}

Seeds germinate quickly in open joints, wall tops, and any surfaces where soil can accumulate. Although many smaller and non-invasive climbers are harmless to masonry walls, 
some mature creepers, shrubs, and trees will cause irreversible damage. The most effective treatment is proper maintenance, but there are many situations where vegetation has already been established and should remove. The plants should be trim close to the wall face or the ground so the condition can adequately check, and root systems can then poison. When plant roots rot away into walls, voids will manufacture, this allows water penetration, and eventually, masonry becomes loose. In this case, it is essential to perform treatment; it may require some excavation of joints, grouting, and pointing. Vegetation clearing is a crucial stage for preservation.

\subsection{Pointing}

Existing pointing can provide evidence about the materials and techniques used in the construction and later interventions. Repointing is the most common intervention on masonry because even the best mortar may tend to erode and need replacement. Although pointing may amount to as little as 5\% of the surface area, it will affect the total appearance and behavior of the masonry. Repointing should match the original in color, texture, design, and application.

Table 2: Material used in the project inside the structure walls was in ratio of 1 lime to 2.75 aggregates.

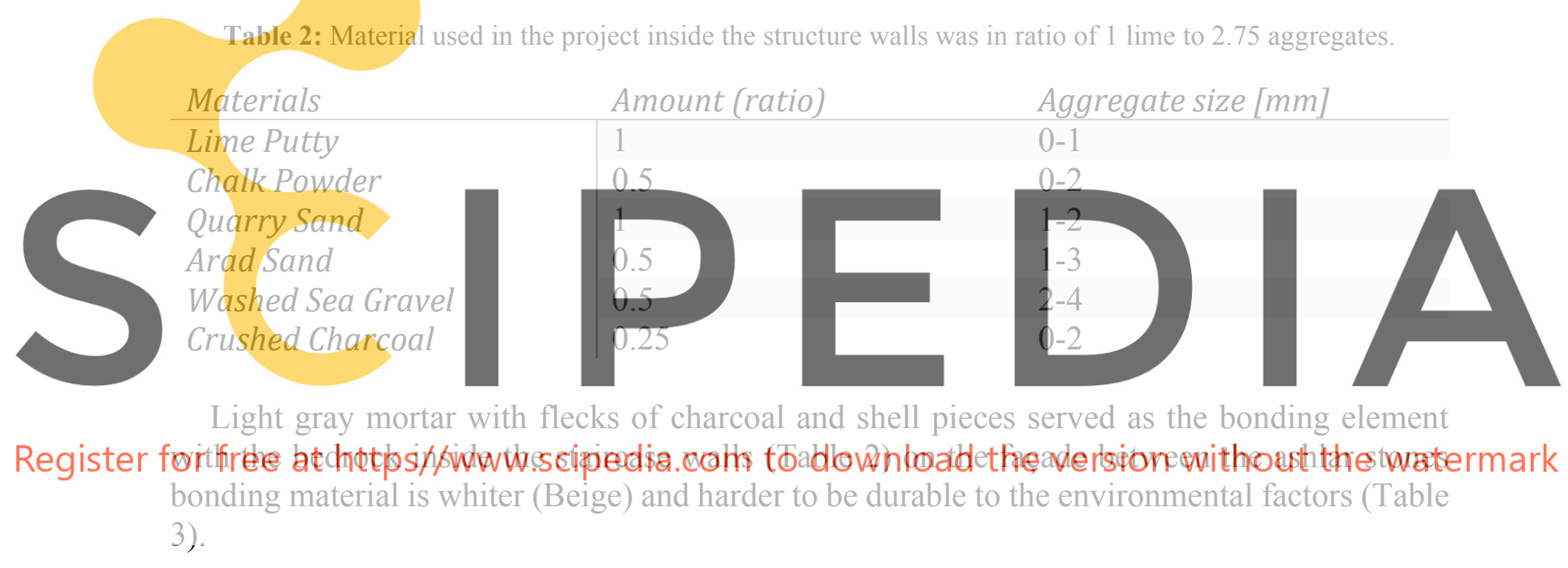

\subsubsection{Preparing the joints}

The existing mortar should remove to a depth of at least $25 \mathrm{~mm}$, or twice the joint width to provide sufficient space. Notably, for thin joints, this rule may need to be modified, but it is always essential to have adequate depth to allow the new mortar to function effectively. Loose dust needs brushing away, and joints flushed out with clean water.

\subsubsection{Applying the pointing}

The wall should be damp to encourage good bonding between the new mortar and the stone. The material should be placed carefully and pressed well into the joint until overfilled, keeping it away from the face of the masonry. Deep and wide joints may need pre-wetted shards of Kurkar stone or pieces of pottery pushed into the mortar. The weather must be suitable; high temperatures or high winds will dry the material too quickly, inhibiting carbonation. The wall should cover with damp canvas and plastic sheeting during the process and for some time 
afterward to slow drying the new pointing.

\subsubsection{Surface finishing}

When the material is no longer wet, but before it has dried up, it should be pressed back into the joint using the appropriate pointing tool to ensure a good bond with the masonry. At that point, when the material is leather-hard, the surface can finish by beating it with a stiff bristle brush to expose the aggregates and perforate it. This action will give not only visually appropriate open texture but also helps water evaporation and allows air to ger into the material to aid carbonation.

\subsubsection{The main stage in successful repointing:}

- Removal old and precarious pointing.

- Cleaning out the joint using a hand-held blower.

- Wet the joints thoroughly.

- Apply the pointing.

- Compress the material with a pointing tool of suitable width.

- Allow mortar to take an additional set.

- Cut back the material to a slight recess around the stones.

- Strike the surface with a churn brush.
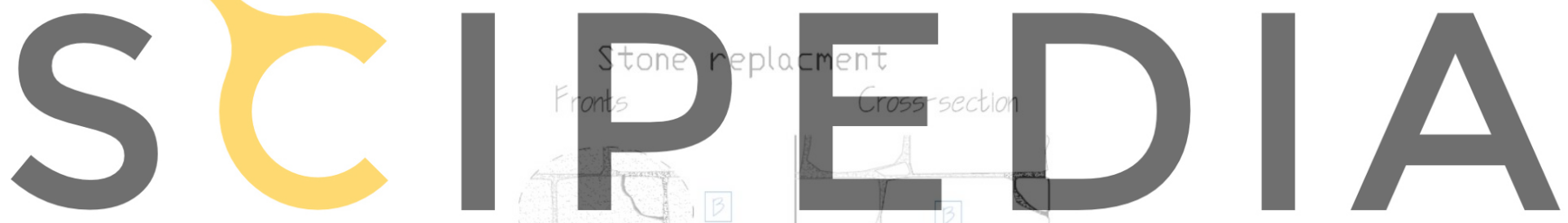

Register for free at https//www.scipedia.com to download the version without the watermark

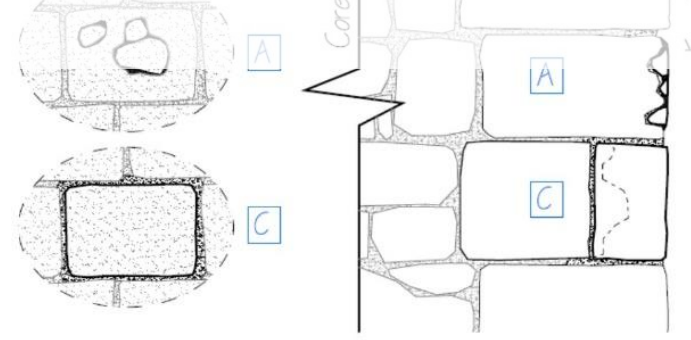

Figure 4: Sketch summarizes the intervention in stone.

\subsection{Stone replacement}

The replacement of stones has always been a fundamental part of historic building repair. The requirement for authenticity demands that proposals for replacement of stone are carefully and rigorously justified [4]. Repairing stone elements in situ plays a substantial role in building conservation. Its design to prolong the survival of stonework by stabilizing faults, filling voids or cracks, and protecting the building architectural from current and historical decay. For 
example, crack encouraging and accelerating further deterioration when the moisture gets in and widens as debris accumulates within them. Eventually, these changes may lead to major structural weaknesses. As a general rule, replacement stone should be the same geological type and appearance, both in color and texture, as the original [5].

The aesthetic effects of replacing stone can also be significant. It is essential to be accurate when taking templates and working the stone. Good mason will help the diminishing contrast between the new part and the original around it (Fig. 3) by ensuring that joint widths around the new stone match the original and that the surface has an appropriate finish. Stone intervention in the monumental stairs project divides into three categories [5] (Fig. 4).

A: A lightly weathered stone with $7-12 \mathrm{~cm}$ façade cavities.

B: Stone with edge cavities from $12 \mathrm{~cm}$ to half stone façade.

$\mathrm{C}$ : A severely damaged stone, over a half-face is missing.

The process of replacement starts with removing the old stone minimum amount of decayed should be removed, with particular care taken to save the adjacent material. Sharp chisels and stone saws used to cut out small parts, but for larger ones and complete stone, it is necessary to use a non-percussive drill, an electric hammer, or an angle grinder. Once the stone removes, all debris in the cavity must be clean. The process of replacement starts with removing the old stone minimum amount of decayed should be removed, with particular care taken to save the adjacent material. Sharp chisels and stone saws used to cut out small parts, but for larger ones and complete stone, it is necessary to use a non-percussive drill, an electric hammer, or an angle grinder. Once the stone remoyes, all debris in the cavity must be clean. The next step in the
process is cutting the new replacement stone to the required size ('sawn six sides') from the
appropriate antique stone. Restoration of historic stonework detail requiles some hand-cutting
by chisel and hammer.
Eventually, to install the new replacement stone, the cavity should be well darnp, and then a
bed of mortar (Table 3) is applied to the back of the hewn space, base, and other side joints. Previous to being into place, the replacement stone should be quite wetted to stop it sucking

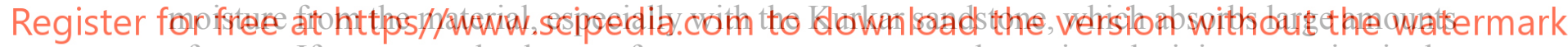
of water. If necessary, lead, stone fragments, or pottery can be set into the joints to maintain the position of the new stone and prevent the mortar from slumping. The process of stone replacement differs from one category to another: (Fig. 4).

A: complete small cavities in the stone façade with paired stone.

B: fill cavities at the edges using a stone with a straight face and sides.

$\mathrm{C}$ : removing the front of the damaged stone to a depth of $25-30 \mathrm{~cm}$ and complete it with antique ashlar stone.

Table 3: Material used in replasing stones was in a ration of 1 lime to 2.5 aggregates.

\begin{tabular}{l|ll} 
Materials & Amount (ratio) & Aggregate Size [mm] \\
\hline Lime Putty & 1 & $0-1$ \\
Chalk Powder & 0.5 & $0-2$ \\
Quarry Sand & 1 & $1-2$ \\
Arad Sand & 0.5 & $1-3$ \\
Sea Gravel & 0.5 & $2-4$
\end{tabular}




\subsection{The arch bridge restoration}

Casting technique gives the structure flexibility and elasticity an example of this; the carried vaults wall stands firm 2000 years to these days. The arch bridge was constructed in the interval between the apparent massive pier and the western (temenos) wall, holding the stairs leading up to the Church platform. In the Byzantine period, the arch built lower than the Roman one, the carve into the temenos wall $35-40 \mathrm{~cm}$ in-depth, and built the arch bridge with the stairs above it. The new restorer arch built from new ashlar sandstone made of the same geological type the architect divided the arch bridge into seven-line of stone from each side and line number eight as a keystone.

The arch bridge restoration project starts with placing iron mold to hold the stones every one weighs an average of 400 pounds carried out by a crane while the aggregate weight of the arch is 45 tones. The construction began on one side and continue the following day on the other side to make a balance, every day we built one line of stone, each one needed to be adjusted, occasionally cut, and rubbed [7]. We have to be very precise to construct an arch stone should be balanced and facing towards the center point of the arc and located at the same radius distance. Keystone should be placed in one day to lock the arch and start shifting the weights aside and down to the walls.

Bonding material used to connect the arch stone is a hydraulic mortar based on natural hydraulic lime (NHL 5) mixed with 2.5 well-graded aggregate, sand, and crushed stone. To aid workability Lime Putty added up to a maximum of $10 \%$ to the mixture.

\section{SUMMARY}

The monumental Byzantine stairs are one of the remarkable architectural and archeological findings in the administrative area of Caesarea ancient city. The cultural and archeological significance of the project besides revives the place spirit that is the central concern in Caesarea's historic fabric. Proper planning, monitoring, and ongoing effective maintenance are vital to the stone building long-term preservation, obviate the need for more disturbing and costly intervention also sustain the heritage values of the building: a principal aim of conservation.

The goal of the project presented in this article is dealing with severe damage to the staircase caused by ongoing exposure to harsh weathering conditions, either stabilize and capability the stairs structure to restore the massive bright arch. The project involved detailed documentation of the staircase: assessment of the stones' current condition, detailed treatment program, investigation on stone deterioration state, also adjusted and detailed restoration program.

The findings of the project show that to deal with restore a new bridge arch, a challenge that the Roman and Byzantian faced thousand years ago and overcame it with the knowledge and technology that was available then, it is vital to bring to life and use traditional building technologies either original bonding materials integration with contemporary technology and information. Through experience and in-depth observation of things, we can overcome the challenge we face today.

Since it is not possible to avoid deterioration, a regular inspection and maintenance program is an essential and suitable solution. The new intervention must adopt the conservation principles to be durable and stable against environmental conditions, either identified and reversible. 
We cannot think about existence without history and tradition that have defined roles. We are responsible for balance history and modern technology in professional ways. With all these heritage values around us, we have to be curious about discovering new knowledge that will help us to develop. There is a vast heritage to look after, to carve memory, and to preserve for the next generation. Thanks to conservation work and restoration of Byzantine period visual integrity for reviving the spirit of the place, the staircase structure that has disassembled and was in a coma for 1380 years brought to life.

\section{REFERENCES}

[1] Ayolon, E. and Izdarechet, A. Caesarea Treasures. Jerusalem, Vol. I., (2011), pp. 93-96, Vol. II. (2011), pp.169-180.

[2] Fuhrmann, N.Y. and Porath, Y. Ancient Caesarea: Conservation and Development of a Heritage site. Israel Antiquities Authority, Jerusalem (2017), pp. 3-7.

[3] Joseph, P. A Walk to Caesarea: A Historical Archaeological Perspective. Jerusalem (2018), pp. 1-8, 30-40.

[4] Maklada, N. Caesarea: Conservation of the South Wall. Conservation of Cultural Heritage. Conservation Administration, Israel Antiquities Authority, Jerusalem, Vol. I., (2018), pp. 48-52 (In Hebrew).

[5] Maklada, N., Saad, Y., Schaffer, Y., Gendelman, P., Sha'altiel, Y., Greenfeld, E. and Rosental, I. The Crusader Wall of Caesarea Resurrected: A Conservation Stonework Project, In: Siegesmund, S. and Middendorf, B. (Eds.): Monument Future: Decay and Conservation of Stone, Proceedings of the $14^{\text {th }}$ International Congress on Deterioration and Conservation of Stone, Vol. I., and Vol. II, Mitteldeutscher Verlag (2020), pp. 817-822.

[6] Odgers, D., Henry, A., Martin, B. and Wood, C. Stone: Practical Building Conservation. English Heritage. Ashgate Publishing Limited, Farnham, UK, (2012), pp. 47-67.

[7] William, R.P. Practical Masonry. Fifth Edition, London, (1904), pp. 11-18.

Acknowledgements. The conservation and restoration work in Caesarea National Park were held due to the Caesarea Development Corporation and funding from the Edmond de Rothschild Foundation for their generous donation which enabled the operation of this project. Many thanks also to the Israel Antiquities Authorities and the Conservation Department for management the archeological excavation with conservation and restoration the archeological ruins. Last thanks to my amazing wife for constant support and encouragement that never ends and Shada Hadid for the spelling checking. 